\title{
Correction of tear trough deformity with a cohesive polydensified matrix hyaluronic acid: a case series
}

This article was published in the following Dove Press journal:

Clinical, Cosmetic and Investigational Dermatology

25 June 2015

Number of times this article has been viewed

\author{
Jürgen Huber-Vorländer \\ Martin Kürten \\ Fort Malakoff Klinik, Mainz, Germany
}

Correspondence: Jürgen Huber-

Vorländer

Fort Malakoff Klinik Mainz GmbH,

Rheinstrasse 4K, 55II6 Mainz, Germany

Tel +49 6I3। I46767

Fax $+496131 \quad 146777$

Email dr.huber-vorlaender@malakoffklinik.de

\begin{abstract}
The tear trough or infraorbital hollow is a challenging area to treat, and only a few fillers are suitable for this delicate area. We report on a European case series of six subjects with mild to severe tear troughs who received treatment with cohesive polydensified matrix $\left(\mathrm{CPM}^{\circledR}\right)$ technology hyaluronic acid gel (Belotero ${ }^{\circledR}$ Balance). The product was injected as small depots (up to ten small boli $0.2 \mathrm{~mL}$ maximum each per side) at the supraperiosteal level along or below the orbital rim. Follow-up visits took place at 1, 3, 6, and 9 months after injection for independent evaluation of the clinical effect using the Merz Aesthetics Scale ${ }^{\mathrm{TM}}$ for infraorbital hollows and the Global Aesthetic Improvement Scale. Adverse events were also recorded. Mean hollowness scores were considerably improved compared with baseline in all subjects. In all women, the improvements remained throughout the 9-month study, with none reverting to their baseline score. Subjects' satisfaction with treatment was very high throughout the study, and all women stated that they would repeat treatment with the same product. The CPM hyaluronic acid gel was well tolerated. CPM hyaluronic acid gel is a safe and effective treatment for the tear trough area.
\end{abstract}

Keywords: Belotero ${ }^{\circledR}$ Balance, cohesive polydensified matrix $\left(\mathrm{CPM}^{\circledR}\right)$, hyaluronic acid, infraorbital hollow, tear trough

\section{Introduction}

The eyes are the focal point of the face, and for most people, the eye area is the first place where they notice signs of aging. According to the results of the recent "Face Value" beauty survey, conducted in nearly 3,000 women from France, Italy, Spain, Russia, and the UK, more women would consider treatment around the eyes than any other facial area, including $62 \%$ of women aged $26-45$ years and $74 \%$ of women aged $46-64$ years. ${ }^{1}$ Tear trough irregularities in particular can result in dark shadows under the eyes, so patients often complain that they look more tired and older than they really are or feel.

The tear trough, also known as the nasojugal groove, is the medial third of the periorbital hollow and extends from the inner corner of the eye in a semicircular arc. ${ }^{2}$ Numerous factors are thought to contribute to the presence of the tear trough, including atrophy and a downward shift in the malar fat pad as well as the cheek fat compartment, the bulging of orbital fat above the trough, the tethering effect of the tear trough ligament, differing skin thickness and texture above and below the trough, and agerelated bone loss (infraorbital rim and maxilla). ${ }^{3,4}$ In some individuals, the condition is also congenital, with an apparent lack of soft tissue overlying bone in the area of the trough. While tear trough deformities become more common and accentuated as people age, they are also often present in younger individuals. 
In recent years, there has been considerable interest in nonsurgical treatment of the tear trough using injectable products such as hyaluronic acid (HA) to temporarily fill the depression. However, this region has several anatomic features that are challenging for the injector. First, the skin is extremely thin and translucent, and depending on the filler injected, there is a risk of visible lumps or the Tyndall effect, a bluish discoloration due to the optical properties of the filler used. The vascularity of the tear trough area means that the physician must inject carefully or risk bleeding and bruising. The area is also very susceptible to edema because of compromised lymphatic drainage in the superficial suborbicularis oculi fat compartment. ${ }^{5}$

Cohesive polydensified matrix $\left(\mathrm{CPM}^{\circledR}\right)$ technology HA gel (Belotero ${ }^{\circledR}$ Balance [previously known as Belotero Basic]), ie, CPM HA (Merz Pharmaceuticals GmbH, Frankfurt, Germany), is an ideal agent for treating the tear trough area. The CPM technology produces a monophasic polydensified gel that combines high levels of crosslinked HA with lighter levels of crosslinked HA in the same product. This provides the product with specific rheological properties suited for the tear trough area, including low elasticity and viscosity and a high tan delta for soft flowing qualities and a homogeneous pattern of tissue integration. ${ }^{6}$ Fillers with these properties are less likely to cause malar edema in the tear trough area because there is less compression of the lymphatics. ${ }^{7}$ Furthermore, while all HA fillers are hygroscopic, the specific crosslinking technology of CPM HA gel means that it absorbs less water post-injection and is therefore associated with very little postinjection swelling compared with other HA gels used to treat this area. ${ }^{8}$ The gel is approved in Europe and was approved by the US Food and Drug Administration in 2011 for injection into the superficial to mid dermis for correction of facial wrinkles and folds. It produces results comparable with those of other leading HA fillers with a similar duration of effect, and is well tolerated. ${ }^{9-11}$

Treatment of the tear trough is one of the most challenging indications in facial rejuvenation. Appropriate patient selection and application of the correct injection technique is crucial for optimal cosmetic outcomes and tolerability. Patients best suited for tear trough rejuvenation are those lacking festoons, who have no pre disposition for lower eyelid edema and no skin laxity, but good skin tone. Good candidates are those with mild or moderate volume loss in the tear trough region. ${ }^{2}$ Patients with lower blepharoplasty are difficult to treat, but can also benefit from this procedure.

Only one other study, conducted in the USA, has described treatment of the tear trough area with CPM HA gel. ${ }^{12}$ The current case series describes the experience of European physicians and patient satisfaction with CPM HA gel for the treatment of tear trough deformities of varying severity.

\section{Materials and methods}

Individuals presenting with mild to severe tear trough deformities at a private esthetic surgery practice in Germany were recruited in August 2013. The exclusion criteria were eyelid laxity (slow snap-back test), orbital fat prolapse, and prior injection of permanent filler in this region. Tear trough severity was assessed with reference to the Merz Aesthetics Scale ${ }^{\mathrm{TM}}$ for infraorbital hollows. ${ }^{13}$ After a thorough evaluation of the patient in an upright position, the area to be treated was marked and photographs taken. All patients received topical anesthetic cream (23\% lidocaine, 3.5\% tetracaine hydrochloride, $3.5 \%$ tetracaine; University Medical Center Pharmacy, Mainz, Germany). The CPM HA gel could be injected with 27 gauge or 30 gauge needles supplied with the filler, the former requiring less injection pressure. Single small depots (up to ten small boli $0.2 \mathrm{~mL}$ maximum each per side) of the gel were injected at the supraperiosteal level along or below the orbital rim in the tear trough region according to the technique described in a recent publication. ${ }^{14}$ Injection in the medial part of the tear troughs was performed at a deep dermal level in some patients. After injection, the filler was gently molded with a Q-tip for even distribution. Follow-up visits were planned at 1, 3, 6, and 9 months after injection for evaluation of clinical effect and adverse events. Photographs were taken before treatment, after treatment, and at each follow-up visit to judge the success of treatment. At each visit, a physician not involved in or attending the injection session rated improvement on two scales, ie, the Merz Aesthetics Scale for infraorbital hollows (0, no hollowness; 1 , mild hollowness; 2 , moderate hollowness; 3 , severe hollowness; 4, very severe hollowness), and the Global Aesthetic Improvement Scale (GAIS; 0, worse; 1, unchanged; 2 , improved; 3 , much improved; 4 , greatly improved). Immediately after injection, the treating physician rated distribution of the material and its malleability. At each follow-up visit, the independent rater also evaluated the naturalness, evenness, and antiaging effect of the treatment. Subjects rated their satisfaction with treatment on a 6-point scale (1, very good; 6, poor); they were also presented with a series of statements at each follow-up visit and asked to indicate how much they agreed with them ("very true" to "not at all true"). Tolerability was rated on a 3-point scale (1, very good; 2 , good; 3, poor). Adverse events were assessed throughout the study. All subjects provided their written informed consent. 
This study protocol conformed to current ethical guidelines according to the 1975 Declaration of Helsinki.

\section{Results}

A total of six women ranging in age from 34 to 65 years were treated for tear trough deformities with CPM HA gel. Two women were graded as having mild hollowness, one with moderate hollowness, two with severe hollowness, and one with very severe hollowness (Table 1). None of the women had received any previous tear trough treatments. The total volume injected for both eyes depended on the severity of the tear troughs and ranged from 1.2 to $3.8 \mathrm{~mL}$, injected as $8-10$ boli of $0.1-0.2 \mathrm{~mL}$. None of the women required more than one treatment session. Figures 1-4 are before and after photographs showing continued correction throughout the 9-month follow-up period.

\section{Physician rating}

When using the Merz Aesthetics Scale, five of the six women had no hollowness immediately after injection. In one woman, who had very severe hollowness before treatment, the score improved to moderate hollowness (Table 2). In all women, the improvements remained throughout the study, with none reverting to their baseline score. At 9 months, five of the six women had a score of 1 (mild hollowness) or less. The woman with very severe hollowness (score 4) at baseline had a score of $1-2$ at 9 months, indicating only mild to moderate hollowness. Physician ratings according to GAIS scores were "improved" to "greatly improved" throughout the study and remained as "improved" to "much improved" in all women at 9 months (Table 2).

After all injections, the product was described as having good to very good distribution and good to very good malleability. The blinded physician was also asked to rate the naturalness, evenness, and antiaging effect of the product at each visit. For each of these parameters, the product was rated as good to very good in all the women at every follow-up visit.

\section{Subject rating}

Subjects' satisfaction with treatment was very high throughout the study. All subjects agreed that the treated area looked natural and felt soft and even at every visit. All women also strongly agreed with the statement that they did not look so tired and that they felt younger than they did before the treatment (Figure 5). The women's expectations of the treatment were met at every visit throughout the study. At the end of the study, four women gave the product a global rating of 1 (very good) and two women gave it a global rating of 2 (good), indicating very good to good satisfaction with the product. At the end of the study, all women stated that they would repeat treatment with the same product when it became necessary.

\section{Tolerability}

The product was very well tolerated throughout the study. As expected, immediately after injection, all women experienced some hematoma and swelling. All cases had completely resolved within 2-8 days, and there were no residual effects in terms of skin discoloration or hardening. Furthermore, no Tyndall effect, palpable product residue, or visible unevenness was observed. There were no reports of any other events over the 9-month follow-up period.

\section{Discussion}

CPM HA gel was very effective at replacing lost volume in this case series of women treated for mild to severe tear trough deformities. The gel has been developed with ideal rheological properties for rejuvenation in this area, including low elasticity and viscosity combined with a high ratio of viscosity versus elasticity (tan delta). ${ }^{6}$ The result is a gel with soft, flowing qualities and a homogeneous and smooth pattern of tissue integration. The gel is easy to inject through small diameter needles and requires a low injection pressure, both of which are important considerations for the delicate tear trough area. The gel was described as easy to distribute, with good malleability and smooth, even, and natural-looking results.

Several studies have analyzed data for the elasticity and viscosity of filler products that exert their effects immediately after treatment, with the intention of differentiating them and predicting their behavior during and after injection. ${ }^{6,8,15,16}$ In one of these studies, rheological data for a range of HA

Table I Baseline characteristics and injected volumes

\begin{tabular}{|c|c|c|c|c|c|c|}
\hline & Patient I & Patient 2 & Patient 3 & Patient 4 & Patient 5 & Patient 6 \\
\hline Age (years) & 48 & 65 & 53 & 57 & 34 & 61 \\
\hline $\begin{array}{l}\text { Mean Merz tear trough severity } \\
\text { score at baseline (both eyes) }\end{array}$ & 3 & 4 & I & 2 & 1 & 3 \\
\hline Total volume injected $(\mathrm{mL})$ & 2.6 & 3.8 & 1.9 & 1.4 & 1.4 & 1.2 \\
\hline
\end{tabular}



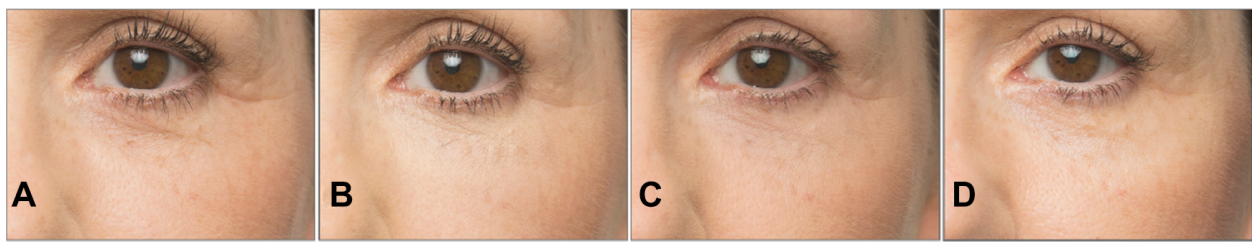

Figure I A 57-year-old female patient with a Merz Aesthetics Scale ${ }^{\circledR}$ score of 2 for infraorbital hollow at baseline (A) received supraperiosteal injections of $0.7 \mathrm{~mL}$ CPM ${ }^{\circledR}$ hyaluronic acid gel per side. (B) 3 months, (C) 6 months, and (D) 9 months after treatment. ${ }^{\circledR}$ Dr. Huber-Vorländer.

Abbreviation: CPM, cohesive polydensified matrix.
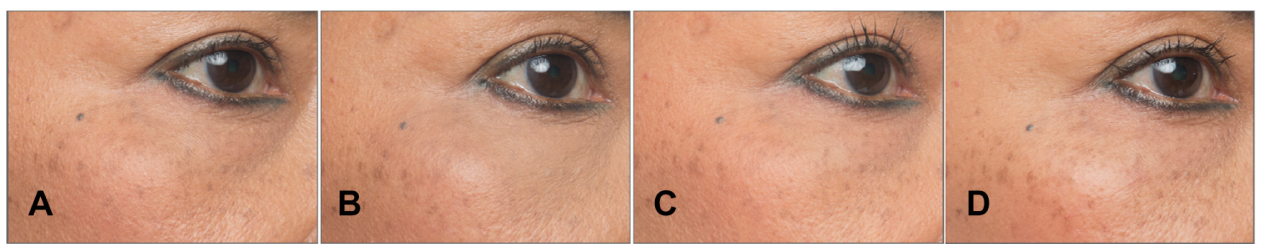

Figure 2 A 53-year-old female patient with a Merz Aesthetics Scale score of I for infraorbital hollow at baseline (A) received supraperiosteal injections of $0.95 \mathrm{~mL} C P M{ }^{\circledR}$ hyaluronic acid gel per side. Complete correction remained throughout the observation period at (B) 3 months, (C) 6 months, and (D) 9 months after treatment. ${ }^{\oplus}$ Dr. Huber-Vorländer. Abbreviation: CPM, cohesive polydensified matrix.
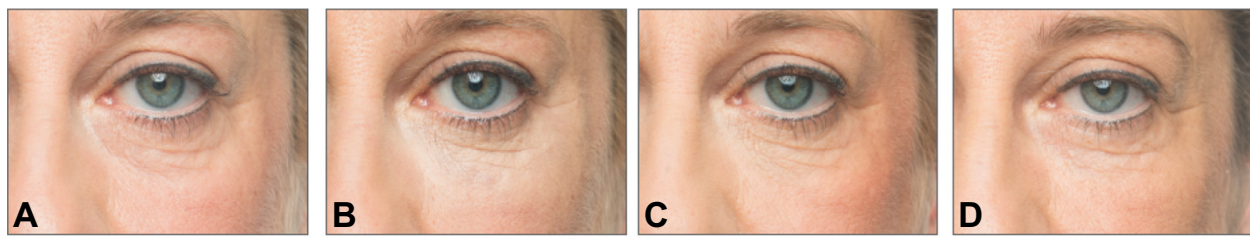

Figure 3 A 57 -year-old female patient with a Merz Aesthetics Scale ${ }^{\circledR}$ score of 2 for infraorbital hollow at baseline (A) received supraperiosteal injections of $0.7 \mathrm{~mL}$ CPM ${ }^{\circledR}$ hyaluronic acid gel per side. (B) 3 months, (C) 6 months, and (D) 9 months after treatment. ${ }^{\circledR}$ Dr. Huber-Vorländer. Abbreviation: CPM, cohesive polydensified matrix.
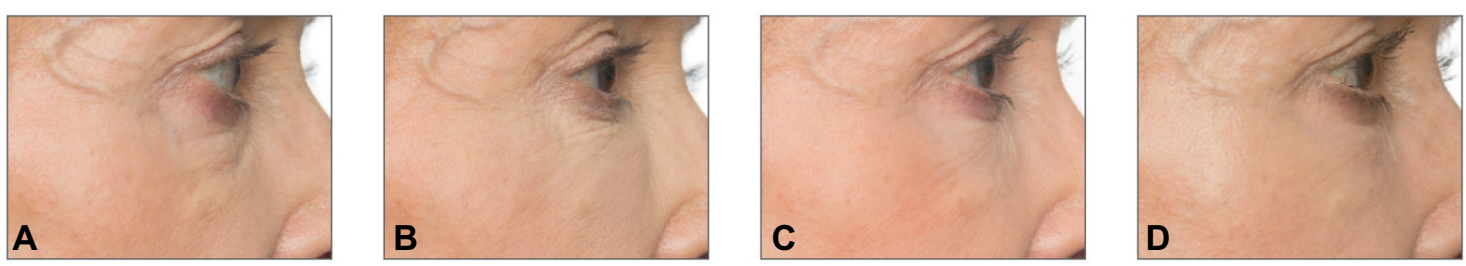

Figure 4 A 61 -year-old female patient with a Merz Aesthetics Scale ${ }^{\circledR}$ score 3 for infraorbital hollow at baseline (A) received supraperiosteal injections of $0.6 \mathrm{~mL}$ CPM ${ }^{\circledR}$ hyaluronic acid gel per side. (B) 3 months, (C) 6 months, and (D) 9 months after treatment. ${ }^{\circledR}$ Dr. Huber-Vorländer.

Abbreviation: CPM, cohesive polydensified matrix.

Table 2 Physician rating of tear trough improvements following injection with $\mathrm{CPM}^{\circledR}$ hyaluronic acid gel

\begin{tabular}{|c|c|c|c|c|c|c|c|c|c|c|c|}
\hline \multirow[t]{3}{*}{ Patient } & \multicolumn{6}{|c|}{ Merz Aesthetics Scale ${ }^{\mathrm{TM}}$} & \multicolumn{5}{|c|}{ Global Aesthetic Improvement Scale } \\
\hline & \multirow[t]{2}{*}{ Baseline } & \multirow{2}{*}{$\begin{array}{l}\text { Immediate } \\
\text { post-injection }\end{array}$} & \multicolumn{4}{|c|}{ Month } & \multirow{2}{*}{$\begin{array}{l}\text { Immediate } \\
\text { post-injection }\end{array}$} & \multicolumn{4}{|c|}{ Month } \\
\hline & & & $\mathbf{I}$ & 3 & 6 & 9 & & $\mathbf{I}$ & 3 & 6 & 9 \\
\hline I & 3 & 0 & 1 & 2 & 2 & 1 & 4 & $2-3$ & $2-3$ & 2 & 3 \\
\hline 2 & 4 & 2 & $\mathrm{I}-2$ & - & - & $\mathrm{I}-2$ & 2 & $2-3$ & - & - & 3 \\
\hline 3 & I & 0 & 0 & $0-1$ & 1 & $0-1$ & 2 & 2 & 2 & 3 & 3 \\
\hline 4 & 2 & 0 & 0 & 0 & 1 & I & 3 & 3 & 3 & 2 & $2-3$ \\
\hline 5 & I & 0 & 0 & 0 & 1 & 0 & 4 & 3 & 3 & 2 & $2-3$ \\
\hline 6 & 3 & 0 & 1 & I & 2 & I-0 & 3 & 3 & 3 & 2 & 3 \\
\hline
\end{tabular}

Notes: Merz Aesthetics Scale ${ }^{\mathrm{TM}}$ for infraorbital hollow (0, no hollowness; I, mild hollowness; 2, moderate hollowness; 3, severe hollowness; 4, very severe hollowness). Global Aesthetic Improvement Scale (0, worse; I, unchanged; 2, improved; 3, much improved; 4, greatly improved).

Abbreviation: CPM, cohesive polydensified matrix. 

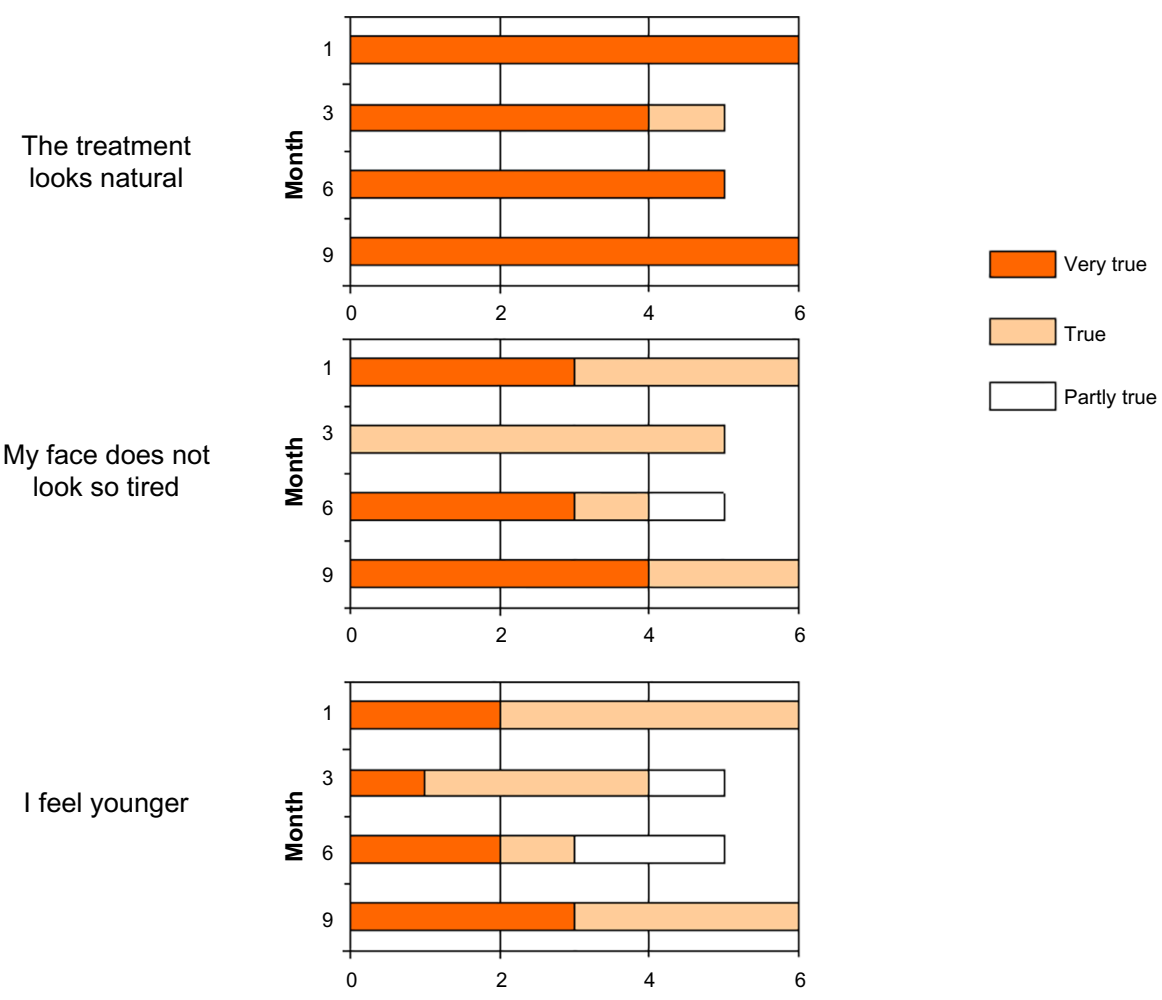

Figure 5 Subject satisfaction with treatment in six women treated with $\mathrm{CPM}^{\circledast}$ hyaluronic acid gel for tear troughs. Abbreviation: CPM, cohesive polydensified matrix.

filler products including CPM HA gel were correlated with data from tissue integration studies to provide a scientific rationale for selecting products for their appropriate clinical applications. ${ }^{6}$ CPM HA gel had the lowest elasticity and viscosity of the tested products, which correlated with its homogeneous pattern of tissue integration after intradermal implantation. ${ }^{6}$ The optimal tissue integration properties of CPM HA gel compared with other HA fillers have recently been confirmed in an ultrastructural analysis using electron microscopy. ${ }^{17}$

The high concentration of HA in this gel $(22.5 \mathrm{mg} / \mathrm{mL})$ provides it with an ideal volumizing capacity and also ensures a long duration of effect. ${ }^{10}$ Physician ratings using both the Merz scale and GAIS revealed at least a one-point improvement in the appearance of tear troughs immediately post-injection as well as after 9 months of follow-up without any requirement for touch-up injection. While individual results may vary, a number of studies with CPM HA gel in other facial indications show that in many patients the effects persist without repeat treatment for 12 months or longer. ${ }^{10,11}$ In the current study, some subjects showed an incremental improvement from month 6 to month 9, which did not appear to be related to the amount of product injected or tear trough severity at baseline. Although follow-up ended at 9 months, it is possible that this effect persisted for longer.
In a similar study, in which CPM HA gel was injected in 46 subjects for the treatment of infraorbital hollows, $87 \%$ of subjects still exhibited at least a one-point improvement from baseline at 10 months. ${ }^{12}$ The results are also at least comparable with those obtained with other HA fillers used to treat this area. ${ }^{2,18,19}$

All the women in this case series were very satisfied with the results achieved, both immediately post-injection and after 9 months of follow-up. The women agreed with the treating physician that the results looked natural and felt soft and even. All women also stated that they looked less tired and felt younger than before they had had the treatment. The women's satisfaction with the product was further confirmed by the fact that all would repeat treatment with the same product when it became necessary.

All dermal fillers have the potential to cause bruising and hematomas, and the vascular tear trough area is very susceptible. Although the occurrence is generally less when materials are injected at the preperiosteal level, hematomas and swelling were observed immediately post-injection in all women. The adverse events were all minor and injectionrelated, and all resolved within 2-8 days. Similar findings have been reported in other studies that have used HA for the tear trough area. ${ }^{2,12,18}$ In a study of 100 patients treated with Restylane ${ }^{\circledR}$ Perlane (Q-Med, Uppsala, Sweden), 75\% reported 
bruising, 33\% reported surface irregularity or lumpiness, and $26 \%$ reported mild edema or swelling. ${ }^{18}$ All patients should be advised that bruising and swelling are potential short-term risks of injection in this area. ${ }^{7}$ No other adverse reactions were reported by the women over 9 months of follow-up, and once the initial events had resolved, tolerability was rated as very good throughout the rest of the study.

Importantly, the Tyndall effect was not observed in either the current study or the US case series. ${ }^{12}$ Histopathological studies have revealed a homogeneous distribution after CPM HA gel is implanted into the dermis, ${ }^{20}$ which may be interpreted as direct microscopic evidence of the effects of viscosity on tissue spread. This intradermal distribution pattern and absence of a discrete bolus of HA filler is thought to preclude the preferential scattering of blue light, which results in the Tyndall effect. ${ }^{6}$

Treatment of the tear troughs with CPM HA gel provides a natural and long-lasting result for all grades of tear trough deformity. The six women in this case series strongly agreed that treating their tear troughs reduced the appearance of fatigue and made them feel younger, and all stated that they would have no hesitation in repeating the treatment in the future.

\section{Disclosure}

This work was partly supported by Merz Pharmaceuticals $\mathrm{GmbH}$. Jenny Grice provided help with medical writing.

\section{References}

1. The Merz Aesthetics Face Value beauty survey. Data on file. Frankfurt, Germany: Merz Pharmaceuticals GmbH; 2012.

2. Hirmand H. Anatomy and nonsurgical correction of the tear trough deformity. Plast Reconstr Surg. 2010;125:699-708.

3. Goldberg RA, McCann JD, Fiaschetti D, Ben Simon GJ. What causes eyelid bags? Analysis of 114 consecutive patients. Plast Reconstr Surg. 2005;115:1395-1402.

4. Wong $\mathrm{CH}$, Hsieh MK, Mendelson B. The tear trough ligament: anatomical basis for the tear trough deformity. Plast Reconstr Surg. 2012;129:1392-1402.
5. Funt DK. Avoiding malar edema during midface/cheek augmentation with dermal fillers. J Clin Aesthet Dermatol. 2011;4:32-36.

6. Sundaram H, Cassuto D. Biophysical characteristics of hyaluronic acid soft-tissue fillers and their relevance to aesthetic applications. Plast Reconstr Surg. 2013;132(4 Suppl 2):5S-21S.

7. Funt D, Pavicic T. Dermal fillers in aesthetics: an overview of adverse events and treatment approaches. Clin Cosmet Investig Dermatol. 2013;6:295-316.

8. Kablik J, Monheit GD, Yu L, Chang G, Gershkovich J. Comparative physical properties of hyaluronic acid dermal fillers. Dermatol Surg. 2009;35:301-312.

9. Kühne U, Imhof M, Kirchmeir M, Howell DJ. Five-year retrospective review of safety, injected volumes, and longevity of the hyaluronic acid Belotero Basic for facial treatments in 317 patients. J Drugs Dermatol. 2012;11:1032-1035.

10. Prager W, Wissmueller E, Havermann I, et al. A prospective, split-face, randomized, comparative study of safety and 12-month longevity of three formulations of hyaluronic acid dermal filler for treatment of nasolabial folds. Dermatol Surg. 2012;38(7 Pt 2):1143-1150.

11. Lorenc ZP, Fagien S, Flynn TC, Waldorf HA. Review of key Belotero Balance safety and efficacy trials. Plast Reconstr Surg. 2013;132 (4 Suppl 2):33S-40S.

12. Hevia O, Cohen BH, Howell DJ. Safety and efficacy of a cohesive polydensified matrix hyaluronic acid for the correction of infraorbital hollow: an observational study with results at 40 weeks. J Drugs Dermatol. 2014;13:1030-1036.

13. Carruthers J, Flynn TC, Geister TL, et al. Validated assessment scales for the mid face. Dermatol Surg. 2012;38(2 Spec No):320-332.

14. Sattler G. The tower technique and vertical supraperiosteal depot technique: novel vertical injection techniques for volume-efficient subcutaneous tissue support and volumetric augmentation. $J$ Drugs Dermatol. 2012;11:45-47.

15. Monheit GD, Baumann LS, Gold MH, et al. Novel hyaluronic acid dermal filler: dermal gel extra physical properties and clinical outcomes. Dermatol Surg. 2010;36 Suppl 3:S1833-S1841.

16. Sundaram H, Voigts R, Beer K, et al. Comparison of the rheological properties of viscosity and elasticity in two categories of soft tissue fillers: calcium hydroxyapatite and hyaluronic acid. Dermatol Surg. 2010;36:1859-1865.

17. Flynn TC, Thompson DH, Hyun S-H, Howell DJ. Ultrastructural analysis of 3 hyaluronic acid soft-tissue fillers using scanning electron microscopy. Dermatol Surg. 2015;41:S143-S152.

18. Morley AM, Malhotra R. Use of hyaluronic acid filler for tear-trough rejuvenation as an alternative to lower eyelid surgery. Ophthal Plast Reconstr Surg. 2011;27:69-73.

19. Viana GA, Osaki MH, Cariello AJ, Damasceno RW, Osaki TH. Treatment of the tear trough deformity with hyaluronic acid. Aesthet Surg J. 2011;31:225-231.

20. Flynn T, Sarazin D, Bezzola A, et al. Comparative histology of intradermal implantation of mono and biphasic hyaluronic acid fillers. Dermatol Surg. 2011;37:637-643.
Clinical, Cosmetic and Investigational Dermatology

\section{Publish your work in this journal}

Clinical, Cosmetic and Investigational Dermatology is an international, peer-reviewed, open access, online journal that focuses on the latest clinical and experimental research in all aspects of skin disease and cosmetic interventions. All areas of dermatology will be covered; contributions will be welcomed from all clinicians and

\section{Dovepress}

basic science researchers globally. This journal is indexed on CAS The manuscript management system is completely online and includes a very quick and fair peer-review system, which is all easy to use. Visit http://www.dovepress.com/testimonials.php to read real quotes from published authors. 